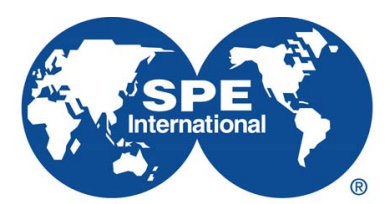

Society of Petroleum Engineers

\title{
SPE-189051-MS
}

\section{Produced Water Treatment by Using Nanofibrous Polyvinylidene Fluoride Membrane in Air Gap Membrane Distillation}

\author{
Rasoul Moradi, Masoud Mehrizadeh, and Hassan Niknafs, Department of Chemical Engineering, Khazar University \\ Copyright 2017, Society of Petroleum Engineers \\ This paper was prepared for presentation at the SPE Annual Caspian Technical Conference and Exhibition held in Baku, Azerbaijan, 1-3 November 2017. \\ This paper was selected for presentation by an SPE program committee following review of information contained in an abstract submitted by the author(s). Contents \\ of the paper have not been reviewed by the Society of Petroleum Engineers and are subject to correction by the author(s). The material does not necessarily reflect \\ any position of the Society of Petroleum Engineers, its officers, or members. Electronic reproduction, distribution, or storage of any part of this paper without the written \\ consent of the Society of Petroleum Engineers is prohibited. Permission to reproduce in print is restricted to an abstract of not more than 300 words; illustrations may \\ not be copied. The abstract must contain conspicuous acknowledgment of SPE copyright.
}

\section{Abstract}

The removal of oil from produced water is one of the main environmental topics in oil and gas reservoir exploitations and industrial operations. In this study, a new method was introduced for efficient and cost effective treatment of produced water by using nanofibrous polyvinylidene fluoride (PVDF) in air gap membrane distillation (AGMD) process. The PVDF membrane was fabricated through electrospinning technique and characterized by means of various methods such as scanning electron microscopy (SEM), liquid entry pressure (LEP) test, gas permeation and contact angle goniometry. The prepared membranes were tested for permeation flux and oil separation efficiency in AGMD process. The results indicate that the optimally modified membrane yields high permeate flux of around $17.5 \mathrm{~kg} / \mathrm{m}^{2} \mathrm{~h}$ and total oil removal efficiency of $99.9 \%$ compared to commercial membranes.

Keywords: Oil and gas, Produced water, Poly(vinylidene fluoride), Membrane distillation, Environmental protection, Nanotechnology

\section{Introduction}

Produced water usually represents a waste product in the petroleum and gas industry. This includes water naturally occurring alongside hydrocarbon deposits, as well as water injected into the ground. Nowadays due to vastness of oil production in the world, coproduced water during the oil and gas extraction operations constitutes one of the main waste streams in the industry. The oil and gas industry produces approximately 14 billion bbls of water annually which contains various contaminates of concern such as oil and grease, dissolved volatile organic compounds, heavy metals, and radionuclides [1].

Produced water is commonly considered as a waste then its management must also be environmentally protective. The acceptable quality of oil-fields produced water for discharging into surface water and/or reinjection must be less than $42 \mathrm{ppm}$ of oil/water, and less than $10 \mathrm{mg} / \mathrm{L}$ of total suspended solids [2]

Treatment of produced water has been attempted and is proven to be an effective option for its safe discharging in environment or reusing for different purposes such as agricultural and human consumptions [3]. Various methods have been developed for produced water treatment. However, their common applications are directly depended to the produced water composition, location, quantity as well as cost and 
energy effectivity [4]. In addition, oil and gas operators have developed some alternatives such as injecting the produced water into the wells and its reusing in oil and gas operations [5]. In comparison with these options, the treatment methodology is proven to be an effective option for produced water management in oil producing countries such as Azerbaijan. Wherein offshore oilfields produced water results in serious environmental challenges and violating Caspian Sea ecosystem.

There are great research interests in improving the current methods and developing the new methods which demonstrate the economic and environmental benefits of produced water treatment [6]. With this respect, the main relevant processes include de-oiling, soluble organic removals, disinfection and desalting $[7,8]$. Ione exchange, cyclone, electrodialysis, deionization, evaporation and membrane based separation are important techniques that effectively could be applied for performing the mentioned processes.

Meanwhile the membrane separation techniques exhibit great potential for satisfying all purposes of de-oiling, organics removal and desalination Membrane processes are a rather new separation process for treatment of produced water [9]. Membrane separation processes, including microfiltration (MF), ultrafiltration (UF), nanofiltration (NF) and reverse osmosis (RO), could be used to treat produced water and generate water with high standards to meet regulations. The driving force of the above-mentioned membranes processes is pressure gradient $[10,11]$.

Numerous studies have been reported in literatures for implementation of membranes in treatment of produced water $[11,12]$. In fact, the development and applying of the new membrane techniques in produced water treating, as well as fabrication of the efficient membranes for this purpose, is an ongoing field of investigation yet [13].

One of the promising techniques to treat produced water is membrane distillation (MD) which demonstrated high performance in various applications such as food industry and fresh water production [14]. Air gap membrane distillation (AGMD) separation process employs a hydrophobic membrane which in one side has a direct contact with hot feed stream and on the other side a cold distillate stream separated cy conductive sheet form air gap section of membrane. Vaporized water molecules pass through the membrane micrometric pores from the hot section toward the cold side. For treating hot brines, if reverse osmosis (RO) process was to be used, the feed should first be cooled which requires some energy, but AGMD process can treat hot feed streams without cooling which is an advantage of AGMD over RO process. Furthermore, the application of AGMD process above $100^{\circ} \mathrm{C}$ eliminates porous substrates which are required for low temperatures $[15,16]$.

In fact, conventional membrane methods suffer from disadvantages especially in the terms of high energy consunming and low efficiency. Therefor, exploring the cost efffective methods such as MD is crucial issue to addreseing common abstackes in efficient treatmnet of the produced water. For this purpose, fabrication of high performance membranes and developing the new experiments are two important approaches.

As reported in the previous studies various types of polymeric membranes are synthesized and employed in oily wastewater treatment [17-20]. Lia et al [21], used polyvinylidene fluoride (PVDF) membranes modified by aluminum nanoparticles to treat oilfield produced water. Bilstad and Espedal [22] studied the MF and UF membranes in the case of North Sea field produced water processing. Abdullah et al [23] implemented different types of polytetrafluoroethylene (PTFE) commercial membranes in MD process for this purpose. In addition, there are some works dealing with application of ceramic membranes. Ebrahimi et al [24] investigated tubular ceramic membranes with different pore sizes for efficient treatment of oilfield produced water. Same author in another work studied ceramic membranes efficiency in different onshore and offshore production condition for treatment of relevant produced water Operations [25].

Despite of all mentioned studies, there is no work about application of new emerging nanofibrous membranes in treatment of oily wastewater. The present work dealing with implementation of these kind of membranes in MD method for treatment of oily wastewater as well as oilfield produced water. For this purpose, nanofibrous PVDF membrane was prepared using electrospinning technique. The membrane characterization was performed by using scanning electron microcopy(SEM), gas permeation test, liquid 
entry pressure (LEP) and wettability measurements. The produced nanofibrous membrane was employed in AGMD experiments to treat lab-made oily wastewater and real samples from different gas and oil fields in Azerbaijan. The AGMD setup was implemented using hot feed of produced water and cold stream of water in two sides of membrane module. The experimental results indicate that introduced nanofibrous PVDF membrane has superior efficiency in comparison with conventional ones.

\section{Materials and Methods}

Polyvinylidene fluoride (PVDF. 99.9\%, MW = $200000 \mathrm{amu}$ ) used in this work was purchased from SigmaAldrich, USA. Commercial PVDF membrane was purchased from Millipore Merck, Germany. Tween-80 was employed as a surfactant in producing of model solution and was purchased from Sigma-Aldrich. N, N-Dimethylacetamide (DMAc, >99\%) was also supplied by Sigma-Aldrich. Acetone and all employed solvents were in analytical grades and prepared from Merck. Double distilled water used in all experiments.

\section{Preparation and characterization of produced water}

Produced water from the oil field was treated by AGMD experiments. The produced water was supplied by Nafte-Shomal Company, Tehran, Iran. Like other fields natural produced water, it consists of dissolved compounds and suspended particles. Removing sand and undissolved particles from the feed is an important process to prevent any pipe blockage, membrane fouling. For these reasons, some filtration pretreatments have been implemented to the produced water before applying in AGMD process. The typical composition of Caspian Sea produced water composition is shown in Table1.

Table 1-Characteristics of the produced water model sample and real sample

\begin{tabular}{ccc}
\hline Property & Model Sample & Real Sample \\
\hline Dispersed oil $\mathrm{mg} / \mathrm{l}$ & $140 \pm 10$ & $740 \pm 50$ \\
$\mathrm{pH}$ value & $7.1 \pm 0.2$ & $6.0 \pm 0.5$ \\
Conductivity $\mu \mathrm{S} / \mathrm{cm}$ & $200 \pm 5$ & $31000 \pm 10000$ \\
TOC $\mathrm{mg} / \mathrm{l}$ & $60.0 \pm 10$ & $1400 \pm 200$ \\
Oil weight ratio wt $\%$ & 10 & - \\
\hline
\end{tabular}

Oily wastewater model solution was prepared in a heated stirred vessel through mixing waste oil (at $5 \%, 10.0 \%, 25.0 \%)$ and Tween-80, 5.0\% $(\mathrm{w} / \mathrm{w})$, with double distilled water for $60 \mathrm{~min}$ at $45^{\circ} \mathrm{C}$. Then the prepared suspension was subjected to ultrasonication for about 1 hour to get homogenized and the clarified yellowish color appears. Table 1 represents the characteristics of the prepared model solution.

\section{Preparation of nanofibrous PVDF membrane}

Electrospinning technique was utilized to produce nanofibrous PVDF membrane. Precursor polymer solution (15 wt. \%) was prepared by dissolving appropriate amount of PVDF in the mixture of DMAc/ acetone $(6: 4 \mathrm{w} / \mathrm{w})$ solution. The obtained blend solution was homogenized by slightly mixing at $30^{\circ} \mathrm{C}$ for about $5 \mathrm{~h}$ and then sonicating for $1 \mathrm{~h}$.

The homemade setup was employed to spin the prepared PVDF solution on the surface of rotating drum which is mounted by the nonwoven polypropylene (PP) support. The appropriate solution flowrate and applied voltage for continues electrospinning were $0.9 \mathrm{~mL} / \mathrm{h}$ and $18 \mathrm{kV}$ respectively. The distance between the needle and the collector drum was fixed at $8.0 \mathrm{~cm}$ during electrospinning process. In addition, the collector drum speed was kept constant at around 500rpm. After completion of electrospinning the produced nanofibrous PVDF membrane was kept at $50^{\circ} \mathrm{C}$ inside the vacuum oven for about $5 \mathrm{~h}$ to removing solvent residuals. The schematic of the employed electrospinning process is shown in Figure 1. The prepared membranes were employed in AGMD experiments for treatment of produced water samples. 


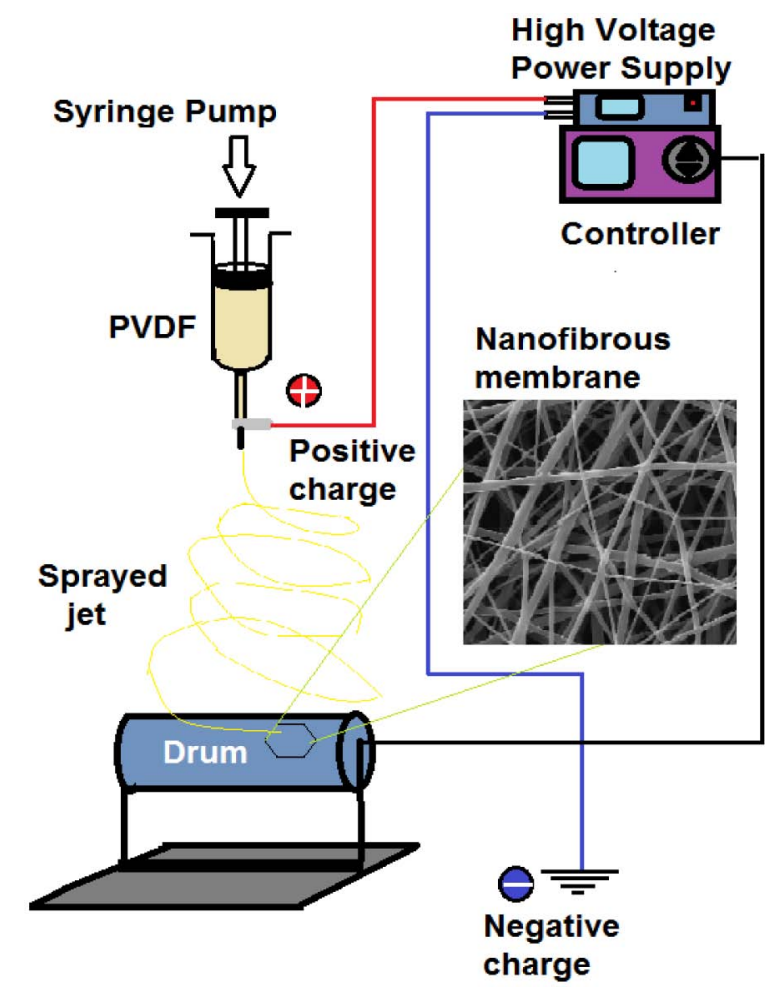

Figure 1-Schematic representation of electrospinning setup.

\section{Membrane characterization}

Scanning electron microscopy (SEM) (JEOL-Hitachi 3500-Japan) was used to investigate the morphology of the membranes. The porosity and pore size of the prepared membranes were analyzed by using weighing and gas permeation tests. The liquid entry pressure (LEP) experiments have been done to obtain the LEP values. AGMD experiments have been conducted to study the membranes permeation fluxes both using produced water and distilled water samples.

\section{Experiments}

AGMD experimental set-up used to test the permeation performance of the prepared optimum membrane for desalination. Both the feed and permeate circulated through the membrane module by means of a doublehead peristaltic pump (Watson Marlow, 323). The temperature of the feed solution was controlled by a heating thermostat (501A, Shanghai experimental instrument Co., LTD, China) and that of the distillate water was controlled by a cooling thermostat (DTY-10A, Beijing Detianyou technology development Co., LTD, China). The inlet temperature of the feed solution into the module was maintained at three different temperature $\left(68,75\right.$ and $\left.83^{\circ} \mathrm{C}\right)$ for two different feed concentration $(0.5$ and $1 \mathrm{~mol} / \mathrm{lit})$ for both AGMD. The effective membrane area of AGMD systems was $0.49 \times 10^{-3} \mathrm{~m}^{2}$. Figure 2 shows schematic of AGMD experimental set-up. In the AGMD configuration, evaporated water molecules at the liquid /membrane interface cross the membrane pores and the air gap chamber to finally condense over the cooling stainless steel metallic plate. The temperature of the cold plat in AGMD was kept at $15^{\circ} \mathrm{C}$. 


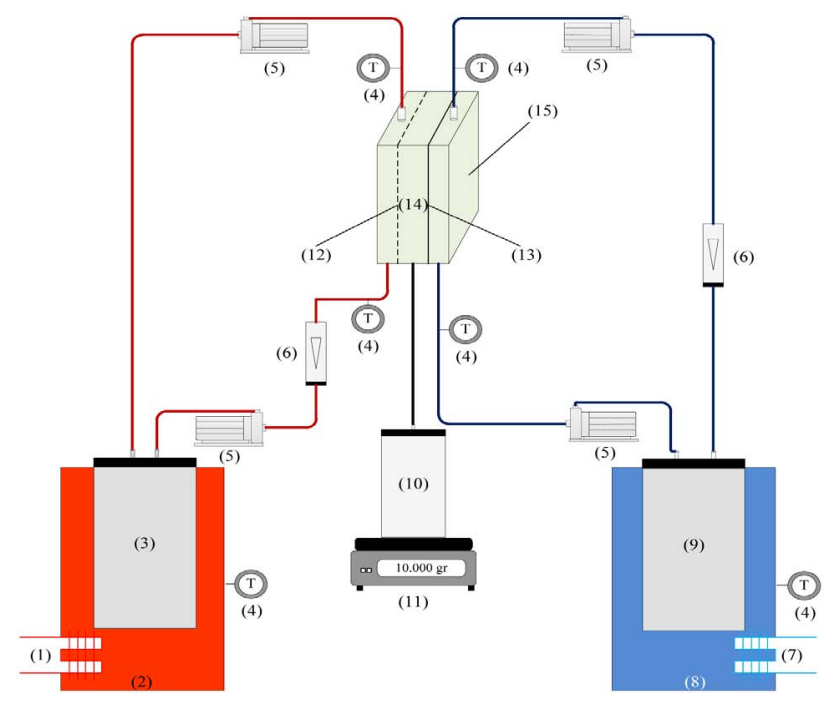

Figure 2-Schematic of AGMD experimental set-up (1) Water heater (2) Hot water bath (3) Feed tank (4) Thermocouple (5) Peristaltic pump (6) Flow meter (7) Water Cooler (8) Cold water bath (9) Cooling liquid (10) Permeate tank (11) Balance (12) Membrane (13) Cold plate (14) Air gap (15) AGMD module

It should be mentioned AGMD experimental tests were carried out for $2 \mathrm{hr}$. At the end, the MD conditions for reaching higher flux were found. Finally, the optimum modified membrane and the unmodified membrane at same preparation condition but without SMM additive were used in MD experiment under the higher MD flux conditions to see the effect of SMM addition on permeate flux and salt rejection. The following equation calculated permeation flux of the membranes:

$$
J=\frac{W}{A \cdot t}
$$

Where $J$ is the pure water flux $\left(\mathrm{Kg} /\left(\mathrm{m}^{2} \cdot \mathrm{h}\right)\right), W$ is the permeation mass of water $(\mathrm{Kg}), A$ is the effective membrane areas $\left(\mathrm{m}^{2}\right), t$ is the sampling time (h). The solute rejection (R) of membrane was obtained from the following equation:

$$
R=\left(1-\frac{C 1}{C 2}\right) \times 100 \%
$$

Where $c_{1}$ and $c_{2}$ are the solute concentration of permeate and feed solution, respectively that measured by water quality meter (Model 900, BANTE Co., China).

\section{Oily water and water quality analysis}

The oil concentration in feed and permeat samples are determined bey employing $n$-Hexane $(\geq 95 \%$ grade purity) as an extractant. The UV fluorescence (TD-500D, Nordatec GmbH, Bremerhaven/Germany) spectrometer was used to anlyse the samples. Total organic carbon (TOC) values were obtained using the TOC cell test by using a photometer (Photolab S6, WTW, Weilheim/Germany).to analyses oil amounts in water sampeles. For detecting the amount of dissolved materials concentrations in feed and permeat streams the electrical counductivity of the samples were measured using a conductivity-meter (HI 9033, Hanna Instruments, Kehl am Rhein, Germany) [28].

\section{Results and discussion}

\section{Membrane characterization}

Field emission scaning electron microscopy (FESEM) images of the synthesized membranes are shown in Figure 3. The PVDF membrane with a net-like morphology is represented in Figure $3 a$ and Figure $3 b$. It 
could be seen that the pores on the surface of the membranes are formed by spinning of the fibers. The image analysis of the FESEM micrografs indicates that the average pore size of the prepared membrane is around $300 \pm 50 \mathrm{~nm}$. The diameters of the produced fibers are in the range of $220 \mathrm{~nm}$ to $470 \mathrm{~nm}$ (see Figure $3 \mathrm{c}$ and $3 \mathrm{~d})$. As shown the pore sizes distribution range are wide $(150 \mathrm{~nm}-350 \mathrm{~nm})$. However, the synthetic membranes comparatively contain island-like parts. These parts influence on the membrane porosity and consequently decrease the separation performanse $[5,29,30]$.

(a)
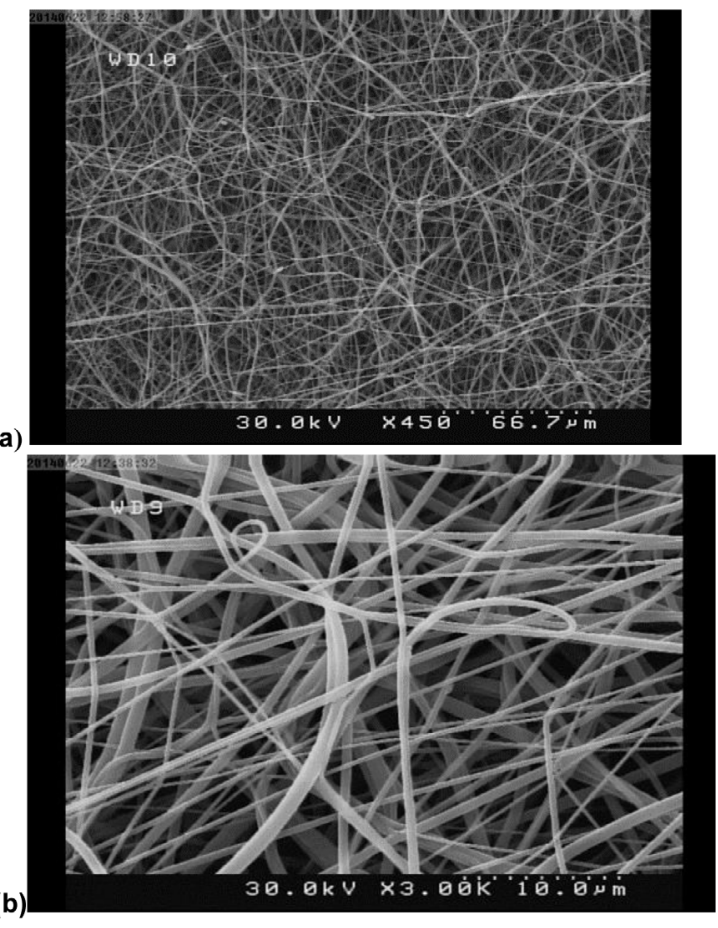

(c)

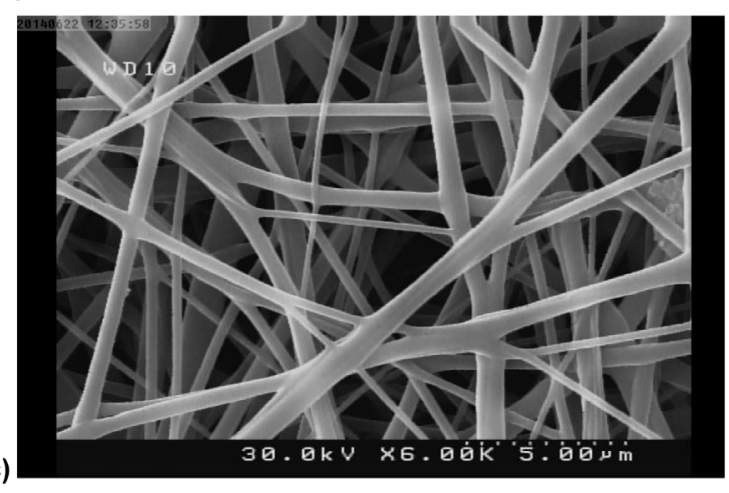

(d)

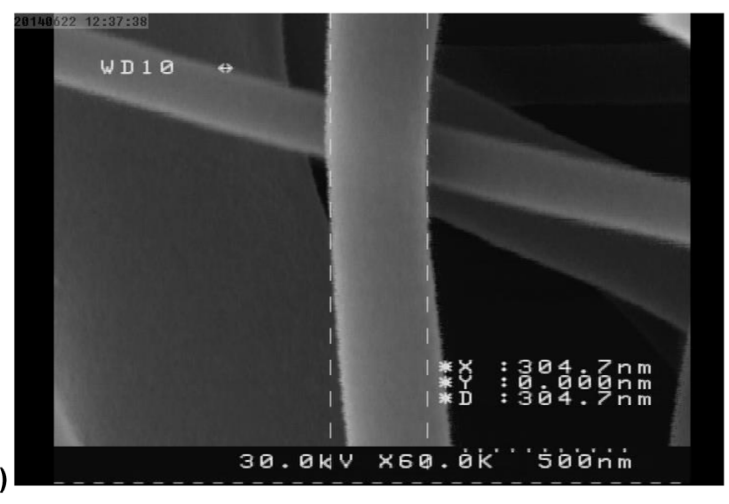

Figure 3-Field Emission Scanning Electron Microscopy (FE-SEM) images of the prepared nanofibrous membranes in different magnifications. 


\section{AGMD experimentation}

As can be seen in Figure 4a, in AGMD process, the permeate flux increases with rising in the feed temperature. The exponential increase of the vapor pressure of the feed aqueous solution with temperature (i.e., Antoine Equation), which enhances the driving force (i.e., vapor pressure difference) for both water and the volatile solutes present in the feed solution. The increases of the non-volatile solute concentration in the feed aqueous solution results in a reduction of the AGMD permeate flux. This behavior is attributed to the decrease of the water vapor pressure, the driving force, with the addition of non-volatile solute in water due to the decrease in water activity of the feed. According to the obtained results, the higher fluxes of AGMD are obtained in oil concentration of $0.5 \mathrm{~mol} / \mathrm{lit}$.
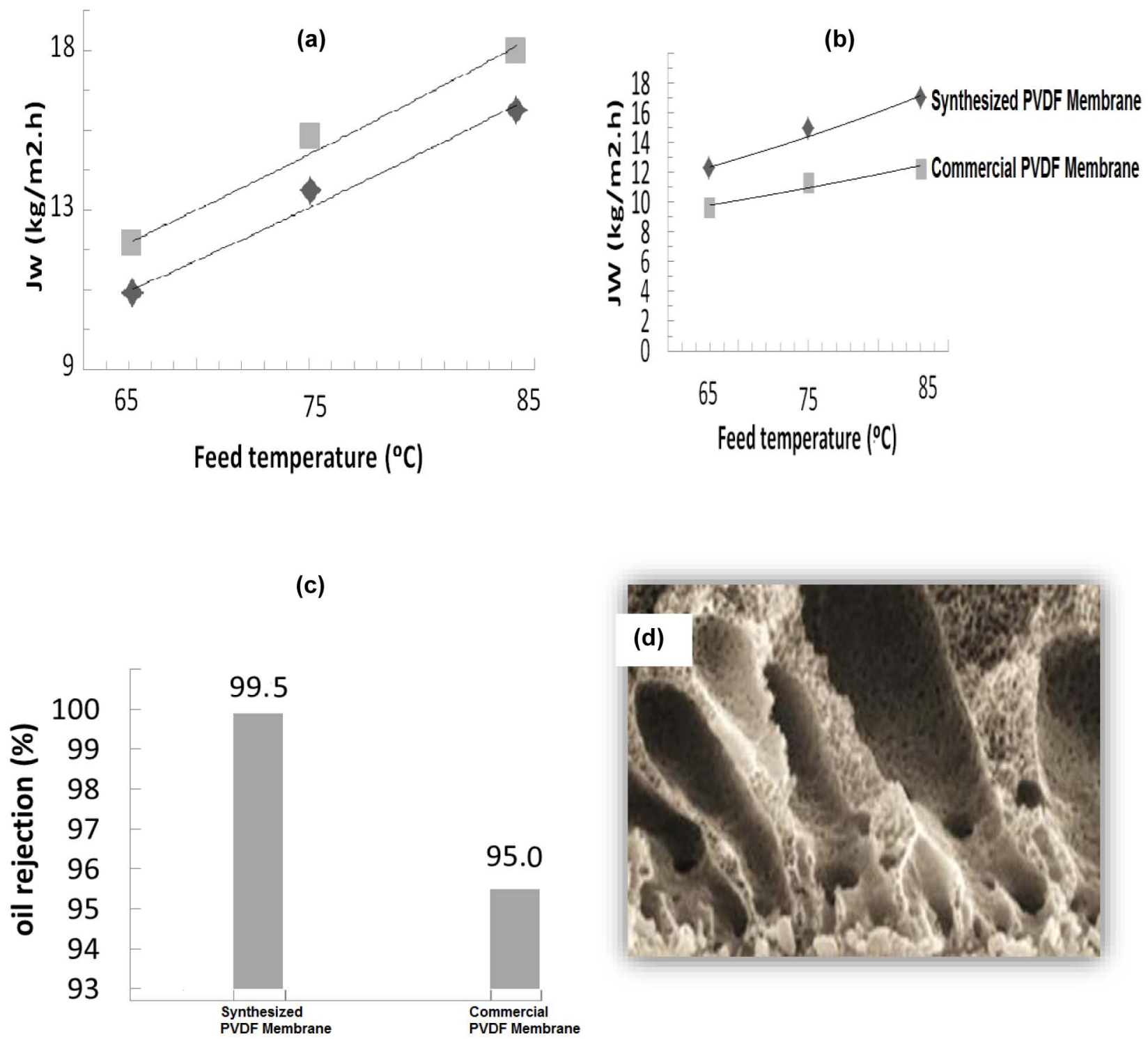

Figure 4-(a) Effect of feed temperatures and Oil concentrations (up:0.5, down:1.0 Mol/lit) on AGMD permeate flux. (b) Variation of AGMD permeates flux as a function of feed temperature for commercial (up) and synthesized (down) PVDF membranes (Feed salt concentration is 0.50 molar). (c) Oil rejection efficiency for commercial (right) and synthesized (left) PVDF membranes. (d)SEM image of membrane cross section.

Finally, in order to compare the permeate flux and salt rejection of the optimum modified membrane with the unmodified membrane prepared at same preparation conditions but without the SMM (with $12 \%$ wt of PVDF, $88 \%$ wt of DMAC and solvent evaporation time of $0.46 \mathrm{~min}$ ), both membranes were tested for 
desalination in the obtained MD conditions of higher flux (feed concentration of $0.5 \mathrm{~mol} / \mathrm{lit}$ and AGMD method).

As can be seen in Figures $4 \mathrm{~b}$ and 4c, both permeate flux and salt rejection of the prepared membrane was higher than the commercial PVDF membrane. In unmodified membranes, low PVDF concentration leads to high porosity and large mean pore size (large voids) resulting in low liquid entry pressure (LEP) values so as described earlier that results in reducing of selectivity. Low contact angle of commercial membranes was because of the absence of nano morphology on the surface of membrane. which amplifies pore wetting and reduces salt rejection efficiency.

\section{Conclusion}

Nano-structured PVDF membrane was synthesized and characterized and applied in treatment of the produced water. In comparison with commercial membrane prepared membranes indicated higher performance in AGMD processes. The nanofibrous PVDF composite membranes were prepared using electrospinning technique and were used for the first time in produced water treatment. The oil removal factor of prepared membrane is obtained in compersion with commercial membrane. The modified membranes reveal higher water contact angles than those of unmodified ones. An AGMD permeate flux $20 \%$ higher than that of commercial membrane was obtained. The oil rejection factor was found to be higher than $99.9 \%$ for the optimally nanofiber PVDF membrane.

\section{References}

1 Li,L. Ryan,A. Nenoff,T. M. Dong,J. Lee,R. Purification of Coal-Bed Methane Produced Water by Zeolite Membranes, SPE Annual Technical Conference and Exhibition held in Houston, Texas, U.S.A., 26-29 September 2004, https://doi.org/10.2118/89892-MS

2 Moradi,R. Karimi-sabet,J. Shariati-niassar,M. Koochaki,M. A. Preparation and characterization of Polyvinylidene fluoride/graphene superhydrophobic fibrous films, Polymers 7 (2015) 1444-1463.

3 Minier-Matar,J. Hussain,A. JansonA.Adham,S. Treatment of Produced Water from Unconventional Resources by Membrane Distillation International Petroleum Technology Conference, (2014), 19-22 January, Doha, Qatar, DOI: https://doi.org/10.2523/IPTC-17481-MS.

4 Curcio,E. Drioli,E. Membrane distillation and related operations: a review, Sep. Purif. Rev. 34 (2005) 35-86.

5 Moradi,R. Karimi-Sabetb,J. Shariaty-Niassara,M. Amini,Y. Air gap membrane distillation for enrichment of $\mathrm{H}_{2}{ }^{18} \mathrm{O}$ isotopomers in natural water using poly(vinylidenefluoride) nanofibrous membrane, Chem. Eng. \& Proc: Process Int. 100 (2016) 26-36.

6 Altaf Hussain, Joel Minier Matar, Samir Gharfeh, Arnold Janson, Samer Adham, Advanced Technologies for Produced Water Treatment, Offshore Technology Conference -Asia, Kuala Lumpur, Malaysia, (2014), 25-28 March, https://doi.org/10.4043/24749-MS.

7 Fang,Y. V.Pham,A. Matsuura,T. J.Santerre,P. R.Narbaitz,M. Effect of surface- modifying macromolecules and solvent evaporation time on the performance of polyethersulfone membranes for the separation of chloroform/water mixtures by pervaporation, J. Appl. Polym. Sci. 54 (1994) 1937-1943.

8 Feng, Shi,B. Li,G. Wu,Y. Preliminary research on microporous membrane from F2.4 for membrane distillation, Sep. Pur. Tech. 39 (2004) 221-228.

9 Ravindran Nair,R. Protasova,E. Bilstad,T. Reuse of Produced Water by Membranes for Enhanced Oil Recovery, SPE Annual Technical Conference and Exhibition held in Dubai, UAE, 26-28 September 2016, https://doi.org/10.2118/181588-MS. 
10 J.Ho,Y. the effect of surface modifying macromolecules on the blood compatibility of polyethersulfone membrane intended for biomedical applications. MSc dissertation, University of Toronto, 1997.

11 Ho,J. Y. Matsuura,T. Santerre,J. P. The effect of fluorinated surface modifying macromolecules on the surface morphology of polyethersulfone membranes, J. Biomater. Sci. Polym. Ed. 11 (2000) 1085-1193.

12 Chong, K. Ch. Lai,S. Lee,K. M. Seng,O. B. Desalination and water treatment characteristic and performance of polyvinylidene fluoride membranes blended with different additives in direct contact membrane distillation, Desalination and water treatment, 54 (2014) 3218-3226.

13 Khayet,M. D.Suk,E. R.Narbaitz,M. J.P Santerre, Matsuura,T. Study on surface modification bysurface-modifying macromolecules and its applicationsin membrane-separation processes, $J$. Appl. Poly. Sci. 89 (2003.) 2902-2916.

14 Khayet,M. Matsuura,T. Progress in membrane surface modification by surface modifying macromolecules using polyethersulfone, polyetherimide and polyvinylidene fluoride base polymers: applications in the separation processes ultrafiltration and pervaporation, Fluid/ Particle Sep. J. 15 (2003) 9-21.

15 Khayet,M. Membrane surface modification and characterization by X-ray photoelectron spectroscopy, atomic force microscopy and contact angle measurements, Appl. Surf. Sci. 238 (2004) 269-272.

16 Khayet,M. Matsuura,T. Preparation and characterization of polyvinylidene fluoride membranes for membrane distillation, Ind. Eng. Chem. Res. 40 (2001.) 5710-5718.

17 Khulbe,K.C. C.Y.Feng, Matsuura,T. Mosqueda-Jimenez,D.C. Rafat,M. Kingston,D. R. M.Narbaitz, KhayetM. Characterization of surface modified hollowfiber polyethersulfone membranes prepared at different air gaps, J. Appl. Polym. Sci. 104 (2007) 710-721.

18 J.A.Prince, Rana,D. Singh,G. Matsuura,T. Jun Kai,T. Shanmugasundaram,T.S. Effect of hydrophobic surface modifying macromolecules on differently produced PVDF membranes for direct contact membrane distillation, Chem. Eng. J. 242 (2014) 387-396.

19 Qtaishat,M. Khayet,M. Matsuura,T. Novel porous composite hydrophobic/ hydrophilic polysulfone membranes for desalination by direct contact membrane distillation, J. Membr. Sci. 341 (2009) 756-767.

20 Qtaishat,M. Rana,D. Khayet,M. Matsuura,T. Preparation and characterization of novel hydrophobic/hydrophilic polyetherimide composite membranes for desalination by direct contact membrane distillation. J. Membr. Sci. 327 (2009) 245-251.

21 D.Suk,E. Pleizier,G. Deslandes, Y. Matsuura,T. Effects of surface modifying macromolecule (SMM) on the properties of polyethersulfone membranes, Desalination. 149 (2002) 303-307.

22 D.E.Suk, Matsuura,T. ParkH.B., Y.M.Lee, Synthesis of a new type of surface modifying macromolecules (nSMM) and characterization and testing of nSMM blended membranes for membrane distillation, J. Memb. Sci. 277 (2006.) 177-185.

23 D.E.Suk, Chowdhury,G. Matsuura,T. R.Narbaitz,M. Santerre,P. Pleizier,G. Deslandes, Y. Study on the kinetics of surface migration of surface modifying macromolecules in membrane preparation, Macromolecules. 35 (2002) 3017-3021.

24 Tang,Y.W. Santerre,J.P. Labow,R.S. Taylor,D.G. use of surface-modifying macromolecules to enhance the biostability of segmented polyurethanes, J. Biomed. Mater. Res. 35 (1997) 371-381.

25 Tang,Y.W. J.Santerre,P. Labow,R.S. D.Taylor,G. Synthesis of surface-modifying macromolecules for use in segmented polyurethanes, J. Appl. Polym. Sci. 62 (1996) 1133-1145. 
26 Tang,Y.W. Santerre,J.P. Labow,R.S. D.Taylor,G. Application of macromolecular additives to reduce the hydrolytic degradation of polyurethanes by lysosomal rnzymes, Biomaterials, 18 (1997) 37-45.

27 Zha,Sh. Yu,J. Zhang,G. Liu,N. Lee,R. Polyethersulfone/Cellulose Acetate Butyrate Hybrid Hollow-Fiber Membranes for Organic-Matter Removal from Produced Water, SPE Journal, April 2017, https://doi.org/10.2118/173787-PA.

28 Ebrahimi,M. Willershausen,D. Ashaghi,K. S. Engel,L. Placido,L. Mund,P. Bouldan,P. Czermak,P. Investigations on the use of different ceramic membranes for efficient oil-field produced water treatment, Desalination, 250(2010) 991-996.

29 Moradi,R. Karimi-Sabet,J. Shariati-Niassar,M. Koochaki,M. A. Preparation and characterization of Polyvinylidene fluoride/graphene superhydrophobic fibrous films, Polymers 7 (2015) 1444-1463.

30 Shoaie,R. Karimi-Sabet,J. Mousavian,S.M.A. Khadiv-Parsi,P. Moradi,R. Optimal modification of poly(vinylidene fluoride) membrane surface by using surface-modifying macromolecules for application in membrane distillation, J. Des. Water Treatment, 71(2017) 62-78. 